\title{
trabalhanecessärio
}

issn: $1808-799 \mathrm{X}$

ano 5 - número 5 - 2007

artigo

\section{O DESIGN SOB A ONIPOTÊNCIA E ONIPRESENÇA DA PEDAGOGIA DAS "MÁQUINAS DE IMAGENS"}

Marcos Antonio Esquef Maciel*

Pode-se caracterizar como Desenho Industrial ou adotando a nomenclatura "Design"[i], uma vertente da atividade do ser humano, recheada de características multidisciplinares, as quais se relacionam com questões culturais, semiológicas, semânticas, cognitivas, psicológicas, tecnológicas, artísticas, sociológicas, ergonômicas, antropológicas e filosóficas. No universo dos estudos científicos, o Design é reconhecido como uma ciência social aplicada, cuja área de conhecimento geral, denominada Desenho Industrial, tem como subáreas 'desenho de produto' e 'programação visual', além de algumas especializações, dentre elas, o 'planejamento de interiores'. Sendo uma ciência aplicada, o Design produz conhecimento a partir da problematização no já exposto leque de questões multidisciplinares.

De modo incipiente, as atividades profissionais relacionadas à busca da padronização dos objetos se desenvolveram de forma artesanal. Com o advento da produção industrial, sob uma nova imposição produtiva, essas práticas foram se aprimorando. Dessa forma, todo um elenco produtivo se evidenciou: o trabalho social foi dividido; novos meios de produção, mecanizados; ingredientes, trabalhadores e padrões se tornaram especializados etc. Neste cenário, sob o poder da nascente burguesia, a ciência e a tecnologia se converteram em poderosas forças produtivas com fins de alavancar a também nascente indústria capitalista. Desta arena, emerge o Desenho Industrial impactado pelas novas tecnologias e presidido pela lógica que comanda as relações de produção, agora reinantes. 
Assim, ao colocarmos esse conjunto de questões na perspectiva do nosso tema de reflexão, a hipótese de que, visando atender ao ajuste acima mencionado, logo se impôs ao designer sua imersão num mundo do controle e da padronização tecnológica dos meios de realização de suas tarefas. Dessa forma, considerando a lógica pós-moderna como diretriz produtiva e a extraordinária utilização dos processos tecnológicos no processo de desenvolvimento de produtos gráficos por parte de um crescente número de designers e, a partir disso, considerando a evidência de que o campo se revestiu de novas características, que em tempo, apontaremos em nosso questionamento, o Design perdeu sua essência funcional-construtivista, herdada da Bauhaus[ii]. Essência esta, que enfatizava criar um homem apoiado numa construção de sociedade, enquanto atividade coletiva, capaz de conciliar trabalho manual e intelectual, que até então estavam divididos, e poderia, ainda, remover as diferenças de classes existentes e aproximar o artista do povo, que pregava o valor de uso e prático aos objetos, que em contrapartida, acentua um outro tipo de valor: o simbólico (de troca). Assim, nesse entorno, o Desenho Industrial (Design) se reveste da busca de soluções formais que exacerbem o valor comercial para bens e serviços.

Ademais, não obstante as observações de Marx apontarem, cientificamente, a importância do conhecimento estético na formação humana, o modo de produção capitalista, particularmente na atual lógica pós-moderna, tem sido pródigo em nos oferecer exemplos paradoxais de uma situação aparentemente descontrolada. Com efeito, o extraordinário desenvolvimento das forças produtivas, que foi observado nos últimos cinqüenta anos, sobretudo no campo tecnológico, estendeu para além das paredes das fábricas e dos centros de pesquisa, o uso cotidiano de máquinas cada vez mais sofisticadas. Da mesma forma, a expansão da indústria cultural e a intensificação do comércio de moda, de beleza e de produtos afins levaram o mundo a uma estetização da vida social mediante a banalização da linguagem artística moderna, outrora por muitos, considerada 'canônica' (REIS, 2005). Portanto, se a banalização das máquinas e a estetização da vida social provocaram um "alívio pós-moderno" frente às limitações e rigores modernos (JAMESON, 1996), paradoxalmente, esses mesmos aspectos induziram a um novo processo de reificação do homem, do trabalho, da vida social. Elas levaram, em suma, a um ajuste ao padrão de acumulação flexível em busca de maior eficiência produtiva, sendo que, sob essa ótica, as intensas tecnologização e estetização da vida social não representaram ganho algum.

Nessa perspectiva, a pós-modernidade promoveu para o campo do design, um afloramento de uma série de questionamentos e contradições, que sempre foram latentes, no entanto, de resolução anteriormente menos premente (DENIS, 2000, p.209). Como o design gráfico é uma linguagem e, imerso nesse processo, sofre uma profunda transformação. A que mudanças nos referimos? Se na modernidade ele objetivava uma comunicação imediata e sem ambigüidades, o controle sobre a mensagem e sua recepção 
regido por princípios de legibilidade, clareza, síntese, relação custo/benefício, associação imediata de elementos visuais e arquétipos já incorporados ao repertório social, agora se vê embrenhado em "quebrar" esses cânones modernistas. Há uma forte tendência a se ater ao inconformismo, à intuição e ao subjetivismo. No entanto, contraditoriamente, como podemos observar, recorre à paródia, ao pastiche, à citação, ao "franco confisco", à intertextualidade e à metalinguagem. Nesse sentido, Jameson reforça a idéia de que o pastiche como uma paródia vazia, não possui mais o seu senso de humor, é a "imitação de um estilo peculiar e único, o uso de uma máscara estilística, [...] mas é uma prática neutra dessa mímica, [...] sem o impulso satírico, sem o riso [...]”. Com base nessas idéias, podese inferir que, se vivemos num mundo em que já não se prescinde mais a inovação estilística, nos resta uma mimese dos "estilos mortos, falar através das máscaras e com as vozes dos estilos do museu imaginário" (1990, p.29-31).

Assim, configurando-se sob o ideário dessa concepção sócio-cultural de mundo, o campo do Design Gráfico plasmou-se por uma estética que passa a ser evidenciada através de fragmentos deslocados, dissociados, possibilitando que sejam franqueadas ao público a reordenação e a recombinação desses elementos da forma que mais the convier. Como demonstra Derrida (apud HARVEY, 2002, p.55), o objetivo é "desconstruir" o poder do autor, já não cabendo, assim, ao mesmo, definir significados ou mesmo oferecer uma narrativa contínua. Adicionando-se ainda, há uma ruptura da "continuidade ou linearidade do discurso e leva necessariamente a uma dupla leitura: a do fragmento percebido ao seu texto de origem: a do fragmento incorporado a um novo todo, a uma totalidade distinta". Assim, é pertinente afirmar que a "colagem/montagem" é considerada pelo autor como a "modalidade primária" de um discurso pós-moderno. Nesse sentido, a continuidade só é dada no "vestígio" do fragmento em sua passagem entre a produção e o consumo. O efeito disso é o questionamento de todas as ilusões de sistemas fixos de representação (FOSTER, apud HARVEY, 2002, p.55).

Em tempo, ainda segundo as reflexões de Harvey (2002, p.53-54), o movimento desconstrucionista - um poderoso estímulo para as formas de pensar pós-modernas possui uma lógica presidida, por exemplo, dos escritores criarem seus textos a partir de palavras, tendo como base outros textos e palavras aos quais se deparam ao logo do tempo, e nos quais os leitores lidam do mesmo jeito. Em decorrência, segundo o autor, a vida cultural é um "entrelaçamento de textos", significa que o que se deseja que seja escrito possui sentidos que não estavam, ou possivelmente, podiam não estar na intenção do autor, isto é, os signos utilizados por nós podem não transmitir o que queremos dizer. Dizendo ainda sob suas palavras, "o perpétuo entretecer de textos e sentidos está fora de nosso controle; a linguagem se opera através de nós".

A força dessas reflexões nos remete a depreender que o mundo como vivemos, o mundo da informação, do espetáculo, da efemeridade das relações, da pujança de luzes e 
imagens que nos cegam e embaraçam a visão, está configurado sob um desenho em que predominam visões fragmentadas e de fragmentos de visões, em que somente se percebe a totalidade à medida que se recompõe na mente de cada indivíduo sempre de forma passageira. Tem-se como grande símbolo dessa época, a Internet (DENIS,200) contudo, a expressão mais corriqueira dessa fragmentação reside no uso cotidiano que se faz de uma televisão com controle remoto. Essa idéia também está presente em Anderson (1999, p.104-105) quando afirma que a televisão (principalmente depois do advento da TV em cores, no início dos anos 70) é um "divisor de águas tecnológico" do pós-modernismo. Para ele, se o modernismo era invadido por "imagens de máquinas", agora testemunhamos que o pós-modernismo é dominado por "máquinas de imagens"[iii]. Nesse sentido, a fragmentação da época atual se manifesta num cinematismo tal que a superabundância de informações disponíveis vai sendo continuamente acrescida de ainda mais informações. Adicionado a essa configuração, todas essas informações vão sendo condenadas à insignificância, pelo simples fato de que o espaço proporcional conferido a elas é ínfimo (DENIS, 2000, p.212).

Por sua vez, Carlsen (1988) aponta que o mundo exterior como se apresenta derramado aos nossos olhos plasma "quadros na tela de nosso cinema interior", os quais são configurados por imagens que, "é claro, são integralmente pessoais". Para ele, ao nos limitarmos a esse único aspecto da 'realidade', teremos como resultado "um autoritarismo incompreendido". O autor analisa, a esse propósito, as imagens com que a mídia nos "bombardeia", impondo-se como uma realidade "positivista e fisicalista" que se sobrepõe as nossas mais íntimas e próprias impressões e visões do mundo. Para ele, ao adquirirmos um respeito talvez exagerado pela "realidade pintada" pela mídia, somos levados a sufocar e obscurecer a relação entre o esclarecimento e a nossa própria ação, empobrecendo, dessa forma, o mundo humano e deformando a realidade. Como aponta Kosik, ocorre aí uma redução do real a uma "uma única dimensão e aspecto, à dimensão da extensão e das relações quantitativas" (2002, p.30). Tais reflexões acerca dessa pujança esquizofrênica e irrefreada de imagens estão também reconhecidas nos escritos de Argan (2005, p.265), ao analisar que o bombardeio de imagens

a que as pessoas estão expostas, principalmente nas cidades, tem por conseqüência a paralisação da imaginação como faculdade produtora de imagens. Essa falta de emissão de imagens tem por conseqüência a aceitação passiva das imagens que formam o ambiente efêmero, mas real, da existência. Isso significa falta de reação ativa, de interesse, de participação. Não é outra coisa senão o que chamamos de alienação. [...] Em suma, é preciso conseguir que a informação e a comunicação de massa não sejam em mão única e, acima de tudo, não impeçam a comunicação dos indivíduos entre si e com o ambiente.

Dentre os aspectos centrais que, historicamente, têm contribuído para essa visão hispostasiada da realidade, certamente se encontra a divisão social do trabalho. A progressiva substituição do trabalho artesanal, do fator de autoconhecimento e conhecimento global da tarefa, da liberdade de criação por parte do trabalhador, pela 
especialização presente no trabalho socialmente dividido, resultou na perda da auto-estima e do reconhecimento do trabalho realizado, fazendo com que os profissionais se tornassem meramente repetidores de tarefas já programadas num modo de produção regido pela "máquina".

Nesse sentido, há muito Marx ressaltava as formas com que o capitalismo se apresentava com vistas à sua reprodução, expansão, à rupturas de fronteiras alterando tradições, e a sensação do perigo de que a grande indústria reduzisse a capacidade de trabalho humano a um mero complemento das máquinas (apud, SANTONI RUGIU, 1998, p.17). Por conseguinte, é pertinente reiterar que, do modo atual como estão plasmadas as forças de produção e acumulação capitalistas, os trabalhadores têm os seus processos de trabalho subordinados de forma mais intensa aos meios de produção. Ao estudar a problemática da reificação, o próprio Marx já havia chamado a atenção para o trabalho morto, cuja realidade, nesse contexto, identificamos como o trabalho contido nos programas eletrônicos dos computadores. Diante disso, é imperativo que nos perguntemos sobre a perda de mestria por parte do trabalhador e em que medida isso importa para a sua transformação em escravo do próprio trabalho. Nessa perspectiva, para Kosik, "o indivíduo já há algum tempo perdeu a consciência de que este mundo é criação do homem" (2002, p.74). Não obstante, ele ressalta, e é pertinente reiterar, que essa realidade aparente pode ser mudada e transformada de modo revolucionário, efetivamente, na medida em que reconhecermos que a realidade é produzida por nós, no sentido de que somos nós mesmos os que a produzem (op. cit., p.23).

Vista do alto, aponta-se que a arena sócio-cultural do final do século XX se configurou "pela saturação de imagens, pela poluição visual, pelo bombardeio da publicidade, pelo olhar como uma forma de consumir" (DENIS, 2000, p.212)[iv]. Nessa linha de pensamento, Guy Debord em suas reflexões acerca desse novo desenho de sociedade, o denominou de "sociedade do espetáculo"[v]. No entanto, é bom que se frise, não como uma crítica dos meios de comunicação, mas como percepção mais aguçada do fetiche dado pela mercadoria numa escala mundial, conformando tudo em imagem e espetáculo, subtraindo os reais valores de uso e deixando transparecer apenas a superfície vazia e "espúria" nos dizeres de Marx - do valor de troca. Isto é, configurou-se um mundo "sem memória, espessura histórica, densidade emocional, conflitos e contradições, apagando, de tudo, o valor social do trabalho e a educação como trabalho que possam formar o cidadão crítico e seletivo" (BUENO, 2003, p.27). De acordo com Debord, vivemos numa sociedade saturada de signos e imagens, configurada pela "onipresença e a onipotência da imagem no capitalismo de consumo" (apud JAMESON, 1994, p.14). Em suma, dito de uma outra forma, por uma expressão do próprio Debord: "a imagem tornou-se a forma final do fetiche da mercadoria" (apud BUENO, 2003, p.27). Pode-se, daí, inferir que o sentido dado para o presente se configura como um "lugar vazio e veloz, que apenas se repete, uma vasta coleção de imagens que a tudo absorve e recupera, exibido como espetáculo e 
mercadoria" (Idem).

Fundamentadas nas idéias expostas, podemos apontar que diversas transformações impactantes foram desenvolvidas sobre o eixo conceitual do design. De acordo com Denis (2000, p.214) há um deslocamento da autonomia relativa tradicionalmente atribuída ao produto, como entidade fixa no tempo e no espaço, para uma noção mais fluida de processo e de integração, bem mais próxima da maneira em que sempre se conceituou o objeto gráfico. Para ele, o primeiro impacto, foi a "substituição dos preceitos funcionalistas do passado por uma visão eclética e híbrida, sem medo de empregar em seus projetos a desordem, o ruído e a poluição visuais". Esta configuração pôde ser verificada a partir da "estética" introduzida por designers que se notabilizaram nas décadas de 1980/90, dentre eles, Neville Brody, April Greiman e David Carson, e de outros mais recentes, nos quais, de acordo com a visão apontada por Denis, mais que um

mero modismo, essa visão de design tem suas bases conceituais profundamente ancoradas na evolução das tecnologias digitais e nas possibilidades que elas trouxeram de superar limites tradicionais com relação à diagramação e à tipografia (2000, p.214).

Com base na diretriz pós-moderna, o sujeito imerso nesse "caldo de pós-modernidade" vive num mundo que se encontra reduzido pelo avanço tecnológico em que as coisas acontecem num cinematismo pujante, cada vez mais rápidas. Tempo e espaço parecem que foram comprimidos, seja em nível socioeconômico ou cultural. O conjunto dessas idéias leva a crer que a ruptura com a ordem temporal das coisas originou um peculiar tratamento com o passado, levando a diretriz pós-moderna a abandonar todo o sentido de continuidade e memória histórica e absorver e "pilhar" a história e tudo que nela classifica como aspecto presente. Dessa forma, os campos do design gráfico e da arquitetura vão se configurar recorrendo ao uso de estilos e obras do passado de maneira eclética e recombinando-os ao seu bel-prazer. Nesse sentido, por exemplo, os designers do movimento Retrô e, dentre eles, Neville Brody revivem e reinventam soluções modernistas do período entre as guerras mundiais, baseadas, em grande parte, no Art Déco (CAUDURO, 2000, p.131-132).

Ao pensarmos que o designer, um profissional que lida com a cultura, com a tecnologia, com imagens, com a arte, e enquanto um sujeito pós-moderno, o mesmo não se apresenta como por inteiro, se conforma como um corpus que parece se dissolver num emaranhado de fragmentos, misturas, representações acríticas, a-históricas e esquizofrênicas, permitindo-se ir em busca do "franco confisco" e de um "alívio pós-moderno" (Jameson), é pertinente observar que o resultado de suas criações esteja recheado dessas características. Por exemplo, em projetos de capas de revistas, de discos, notadamente se comprova essa prática, observando-se que a desordem visual, a improvisação e todo tipo de fragmentos, "sujeiras", "ruídos", desfocalizações, são aproveitados como recursos 
gráficos, tendo como base essa égide estética.

Nessa ordem de reflexão, pode-se apontar, dentre outros, ainda de acordo com Cauduro (2002), "os grafittis, as pichações, os erros, 'ruídos' e falhas de impressão, as hibridações ocasionais, etc. [...]", e também em projetos de marcas que já na sua gênese se apresentam com características transmutáveis, nas quais já estão previstas várias alterações, como por exemplo, o uso de identidades visuais corporativas mutantes ou cambiantes - já que esse é o mundo (do caos) em que vive o sujeito pós-moderno, nada mais lógico que estarem representadas dessa forma - significando dizer que alguns designers se enveredam a desenvolver projetos gráficos e identidades visuais mais "flexíveis", contrariando, de certo modo, dogmas e normas vigentes para o projeto de identidades visuais, as quais tinham que ser conformadas com uma diretriz invariável, a fim de que possibilitassem serem mais facilmente reconhecidas (GARAY, 2003).

Num outro sentido, percebe-se como se tornou possível, barato e simples manipular fontes, espacejamento, entrelinhamento e uma série de outros elementos gráficos que anteriormente eram de domínio quase exclusivo do tipógrafo profissional. Em tempo, cabe uma questão: Se numa configuração produtiva presidida por um novo padrão de acumulação - a flexibilidade - ficou mais "fácil" produzir em meio a tantos recursos tecnológicos, tantas imagens "disponíveis", num mundo em que não há mais memória, "espessura histórica" e, de acordo com o pensamento pós-moderno, na sua defesa da mistura, da diferença, de um mundo sempre mutável, de um inconformismo que contrapõe à rigidez formal e conceitual do modernismo, por que se nota com tanta pujança mimeses, simulacros e "francos confiscos", em muitos dos casos sem nenhuma contextualização com o objeto em si, a se repetirem num "presente cansativo e monótono"?

Considerações finais

Com base nas reflexões expostas, permitimos apontar que o pós-modernismo não pode ser analisado mais como uma simples "ruptura estética ou mudança epistemológica". Deve-se inferir que ele se tornou um "sinal cultural de um novo estágio na história do modo de produção reinante" (JAMESON, apud ANDERSON, 1999, p.66). Ainda, de acordo com Harvey (2002, p.44), também direciona-se que o pós-modernismo, nas últimas duas décadas, tornou-se um conceito que, por conter um campo de opiniões e de forças políticas conflitantes, não pode ser ignorado. Acrescenta-se que a maioria concordaria com a declaração de Huyssens apontar que:

O que aparece num nível como o último modismo, promoção publicitária e espetáculo vazio é parte de uma lenta transformação cultural emergente nas sociedades ocidentais, uma mudança da sensibilidade para a qual o termo "pós-moderno" é na verdade, ao menos, agora, totalmente adequado. A natureza e a profundidade dessa transformação 
são discutíveis, mas transformação ela é. Não quero ser entendido erroneamente como se afirmasse haver uma mudança global de paradigma nas ordens cultural, social e econômica; qualquer alegação dessa natureza seria um exagero. Mas, num importante setor da nossa cultura, há uma notável mutação na sensibilidade, nas práticas e nas formações discursivas que distingue um conjunto pós-moderno de pressupostos, experiências e proposições de um período precedente (apud HARVEY, 2002, p.45).

Nesse sentido, Fredric Jameson (apud HARVEY, p.265) nos invoca a refletir, na sua tese de que o pós-modernismo é a lógica cultural do capitalismo avançado, que a partir da década de 1960 a produção cultural se fincou, subordinadamente, a uma sedimentada e vigente estrutura econômica. Essa perspectiva de análise também está presente em Reis (2006, p.158) ao afirmar que estando a estrutura econômica balizada pelos valores e dogmas da propriedade privada dos meios de produção e de circulação de mercadorias, características intrínsecas do regime de acumulação capitalista, a "vida cultural refletirá esse determinante".

Assim, ao posicionarmos o designer como um profissional imerso e configurado - e porque não, programado - por essa pedagogia regida por essa lógica produtiva e cultural, ele se insere nesse palco como um ator que potencializa e dá forma concreta a promoção de uma cultura do consumismo, para a produção de necessidades e "novos" desejos, mobilizando impulsos e demandas capazes de conservar o status quo, ou seja, a lucratividade da produção capitalista. A esse propósito, ao tomarmos como foco de análise o processo industrial e mercadológico tardio de produtos, ao promover um desgaste (já na sua gênese) do produto, de forma programada com fins psicológicos para os usuários em detrimento de conceber uma mudança estilística baseada em pesquisas nas quais há uma correspondência à sua finalidade (uso) -, percebe-se um consumo que não está proporcional à necessidade, processando o que se denomina de "obsolescência artificial de produtos". Entram em cena, nesse desenho produtivo/mercadológico, todos os ingredientes que transformam, aparentemente, os produtos (as suas características formais, simbólicas), os modismos, os simulacros, a onipotência das imagens como égide produtiva, o marketing para criar e recriar sempre "novas" necessidades, anseios e desejos por parte dos consumidores e adquirir os "novos produtos". Argan (2005, p.261-262) denomina essa configuração de "espiral sem fim do consumismo".

A força dessas idéias traz a tona reflexões críticas, no que diz respeito ao domínio da mercadoria, de Wolfgang Fritz Haug quando indica que na expressão "estética da mercadoria" coexiste uma restrição dupla: a "beleza" - "a manifestação sensível que agrada aos sentidos" - ; do outro lado, uma outra "beleza que se desenvolve a serviço da realização do valor de troca e que foi agregada à mercadoria, a fim de excitar no observador o desejo de posse e motivá-lo à compra (HAUG, 1997, p.16). E continua, considerando que se o valor que foi agregado à mercadoria, sob a forma de "beleza", 
causa satisfação a alguém, então entra em cena a sua "cognição sensível e o interesse sensível que a determina". E ainda, afirma que a "transformação do mundo das coisas úteis desencadeou forças instintivas e meios determinados por suas funções, que padronizam completamente a sensualidade humana ao mundo das coisas sensíveis" (Idem).

Nessa perspectiva de análise, ele indica que em tudo que vivemos, isto é, o que necessitamos, comemos, consumimos, onde moramos, como a nossa vida é organizada, como nos vestimos, nos embelezamos, a maneira como vemos a beleza nos outros, etc., é explorado e configurado por uma força poderosa e dominante, que ele denomina de "interesse capitalista". O que "importa ao capital é a ânsia de lucro", portanto, seu "único planejamento". "As coisas, o país e as pessoas são constantemente triturados pela máquina de moer do capital" (op., cit., p.194).

Adicionado a isso, o autor também aponta como objetivo central para a produção de mercadorias, a sua produção para venda. E existe uma tendência que promove novas mudanças no corpo da mercadoria e na sua forma de uso, que emerge da contradição entre o valor de uso e de troca. Esses valores se inter-relacionam e estão embutidos nas mercadorias. Ou seja, até a última fase da produção capitalista de mercadorias - sua consumação, no sentido do ato de venda das mesmas - revela-se, inicialmente a perspectiva do valor de troca, e quando o consumidor se apropria do produto, manifestase, dessa forma, o valor de uso nele imbricado. Importa, sob a perspectiva do valor de troca, até o final, o valor de uso que está "prometido" na mercadoria.

A esse propósito, Haug afirma que nessa fase "reside desde o princípio uma ênfase acentuada na manifestação do valor de uso que desempenha tendencionalmente, o papel de mera aparência" (1997, p.26). E que o aspecto estético que está colocado na mercadoria - "manifestação sensível e sentido de seu valor de uso" - é separado, nesse momento, do objeto. A sua aparência se torna imprescindível no ato da compra, enquanto objeto (ser). "O que é apenas algo, mas não parece um 'ser', não é vendável. O que parece ser algo é vendável". Num sentido econômico, a aparência estética da mercadoria — valor de uso prometido - se aproxima e se torna ao final, obrigatório, em razão da concorrência (HAUG, p.27). Nessa relação se faz presente, de forma imbricada, o design de produtos, contribuindo, queiramos ou não, para a materialização desse fenômeno mercadológico. Assim, o design, enquanto arte e técnica, encontra-se constantemente balizado de um lado por uma preocupação estética; de outro, determinado por uma ética.

Postas essas considerações, ao tomarmos nessa perspectiva o processo de formação do designer, em meio ao domínio do reino da mercadoria, como produtor de valor simbólico ao produto, imerso à fragmentação característica da experiência pós-moderna, faz-se necessário envidar esforços para que se tornem à luz buscas por narrativas e linguagens 
mais amplas e unificadoras, proporcionando, dessa maneira, uma maior percepção e compreensão de para quem e para quê se projetam produtos de campo do desenho industrial, para que não se perca de vista a totalidade e sua efetiva e real ação social do que é oriundo desses produtos. Acrescente-se ainda, com base em reflexões de André Bueno (2003, p.40) que, ao considerarmos os sentidos humanos como históricos, plasmados ao logo da trajetória histórica humana, os mesmos devem ser educados de maneira a contribuir para que se ampliem suas visões de mundo, contribuindo assim, para uma melhor percepção e compreensão, visando ir muito mais além do que "apenas sombras e fantasmas" que se projetam em paredes de uma dada caverna. Essas idéias reforçam a invocar por uma maior promoção de ações que remetam à melhor reflexão sobre o mundo de forma que se possibilite um maior enfrentamento e uma maior aproximação com os seus reais problemas e sua essência - no mesmo sentido que Karel Kosik proclama em suas reflexões. Ou seja, refletir criticamente considerando o "mundo visível, das aparências", os próprios simulacros da "sociedade do espetáculo", no entanto, não se detendo a eles, aceitando passivamente a lógica produtiva e reprodutiva que 0 rege, mas configurando uma imaginação também crítica e construtiva, que seja capaz de "relacionar esse mundo dos simulacros de massa", característicos dessa sociedade do espetáculo.

Com base nos apontamentos expostos, cabe sugerir que no corpus da formação educacional dos alunos (futuros designers) imersos nesse mundo da superfície, do espetáculo e das coisas passageiras, estejam presentes metodologias projetuais e conhecimentos com fins de que esses futuros profissionais melhor compreendam a real relevância contida em seus projetos, seja de produtos do uso cotidiano ou de peças gráficas, e possam obter um diferencial tal que Ihes permitam transitar com maior segurança em seus campos de atuação. Seria oportuno tomarmos a idéia de Giulio Carlo Argan (2001, p.121) apresentando o "projeto" (que possui uma antítese pós-moderna na expressão "acaso") como um método que compreende em si mesmo, no seu "traçado", a "consciência de todas as técnicas inerentes à sua realização", e que deve estar em correspondência com as demandas práticas no tocante a que, a quem e para que deve servir, não apenas render-se à exigência de um só sujeito ou grupo social. Seria oportuno propor e defender que nos currículos de formação em Designer haja aportes que possibilitem aos alunos enxergar em meio a tanta pujança das luzes da sociedade das "máquinas de imagens", que os remetam a desenvolver uma capacidade de leitura para além das aparências, mais crítica, apurada e mais profunda, não somente sob uma ótica estético-técnica, mas agregada a uma compreensão das múltiplas determinações de como a sociedade capitalista tardia se organiza e quais são os espaços conflitivos e contraditórios desse processo que possibilitarão gerar contraposição ou remediação.

REFERÊNCIAS BIBLIOGRÁFICAS: 
ANDERSON, Perry. As origens da pós-modernidade. Zahar, RJ, 1999.

ARGAN, Giulio Carlo. História da arte como história da cidade. São Paulo, Martins Fontes, 2005. Projeto e destino. São Paulo, Editora Ática, 2000.

BUENO, André. A educação pela imagem \& outras miragens. In: Trabalho, Educação e Saúde. Número 1, Volume 1, 2003. Revista da Escola Politécnica Joaquim Venâncio. Rio de Janeiro: FIOCRUZ/EPJV.

CARLSEN, Jon Bang. "Um rosto na multidão". Folha de São Paulo. Caderno Mais! 29/03/98.

CAUDURO, Flávio Vinícius. Design gráfico \& pós-modernidade. In: Revista FAMECOS, Porto Alegre, n¹3, dezembro de 2000.

. O imaginário tipográfico pós-moderno. Disponível em: http://wawrwt.iar.unicamp.br/GTcompos2002/cauduro.html. Acesso em 01/08/2005.

DENIS, Rafael Cardoso. Uma introdução à história do design. São Paulo. Edgar Blücher, 2000.

GARAY, Boris. Design gráfico e espírito jazzístico: reflexões sobre inovação constante. In: $2^{\circ}$ Congresso Internacional de pesquisa em Design, 2003.

GROPIUS, Walter. Bauhaus: Nova arquitetura. São Paulo. Ed. Perspectiva, 1997.

HARVEY, David. Condição pós-moderna. São Paulo. Edições Loyola. 2002.

JAMESON, Fredric. O pós-modernismo e a sociedade de consumo. In: O mal estar do Pós-modernismo. KAPLAN, E. Ann (Org.). RJ, Zahar, 1990.

Paulo. Ed. Brasiliense. 1994. Reificação e utopia na cultura de massa. In: Crítica Marxista. São

KOSIK, Karel. Dialética do concreto. São Paulo. Ed. Paz e Terra, 2002.

MELO, Chico Homem de. Os desafios do designer. Rosari, 2003, SP.

REIS, Ronaldo Rosas. Educação e Estética. Ensaios críticos sobre arte e formação humana no pós-modernismo. São Paulo: Cortez, 2005.

. Trabalho e conhecimento estético. In: Trabalho, Educação e Saúde. Número 4, volume 2, 2004, p.227-250. Revista da Escola Politécnica Joaquim Venâncio. Rio de Janeiro: FIOCRUZ/EPJV.

. Os dois mundos de Alexander K.: classe, consumo e cultura em Adeus Lênin! In: A diversidade cultural vai ao cinema / Organizado por Inês Assunção de Castro Teixeira e José de Souza Miguel Lopes. - Belo Horizonte: Autêntica, 2006.

SANTONI RUGIU, Antônio. Nostalgia do mestre artesão. Campinas, SP: Autores Associados, 1988. 
[i]“Design é uma atividade criativa cujo propósito é estabelecer as qualidades multifacetadas de objetos, processos, serviços e seus sistemas de ciclos de vida. Assim, design é o fator central da humanização inovadora das tecnologias e o fator crucial das trocas econômicas e culturais. (...) Design trata de produtos, serviços e sistemas concebidos através de ferramentas, organizações e da lógica introduzidas pela industrialização - não somente quando são produzidos em série" (International Council of Societies of Industrial Design - ICSID, 2000). "Design gráfico é uma atividade intelectual, técnica e criativa concernente não somente à produção de imagens, mas à análise, organização e métodos de apresentação de soluções visuais para problemas de comunicação. Informação e comunicação são as bases de um modo de vida global interdependente, seja na esfera dos negócios, cultural ou social. Ao designer gráfico cabe a tarefa de fornecer respostas aos problemas de comunicação de todo tipo em todos os setores da sociedade" (International Council of Graphic Design Associations - Icograda, 2001). Disponível em http://www.lsc.ufsc.br/ edla/design/conceitos.htm.

[ii] A visão pregada pelo manifesto de Walter Gropius, ao fundar em 1919 em Weimar, na Alemanha, era de uma escola que, em seu bojo, apelava para uma nova configuração e construção de sociedade - coletiva - numa tentativa, via ensino, de unir a arte aplicada e as chamadas belas-artes. Adicionando-se a isto, sob as palavras de seu fundador: "[...] 0 nosso objetivo mais nobre é o de criar um tipo de homem que seja capaz de ver a vida em sua totalidade, em vez de perder-se muito cedo nos canais estreitos da especialização. Nosso século produziu milhões de especialistas; deixem-nos agora dar a primazia ao homem de visão (1997, p.27). Em 1933 a Bauhaus é fechada pelo nazismo e, então, vários professores da escola emigraram para outros países da Europa e para os Estados Unidos. Deve-se ressaltar que essa escola é considerada um dos maiores e mais importantes marcos do design, da cultura e da industrialização do século XX.

[iii] "Em uma manobra que chega a ser ingênua, tal o seu idealismo, o pensamento pósmoderno coloca-se contra um sentido crítico de História que articule passado e presente, relacionando a curta e a longa duração, as continuidades e descontinuidades, os grupos e as classes sociais, as regiões e os países, os interesses e os conflitos - em suma, a própria forma complexa e contraditória dos processos históricos e sociais. Tudo é tirado de contexto e tornado apenas linguagem, texto, discurso, imagem, desejo, corpo, deriva e abstrações do tipo. Daí a discutir, com seriedade, o sexo da boneca Barbie, os letreiros dos programas de televisão, as telenovelas como equivalentes a Shakespeare, e o circo eletrônico de massa como efetiva retomada do sentido grego e democrático da pólis grega, é só um passo. Que é dado, com garbo e altivez. Ensinando-nos que a televisão reúne a democracia, a educação, o lazer e a formação do cidadão no mundo pós-moderno, como no mundo grego da cidade-Estado, que reunia democracia, drama e didática em um mesmo contexto. Imagino que os filósofos gregos se revirem nas tumbas diante dessa paidéia pós-moderna" (BUENO, 2003, p.31).

[iv] E, como tratamos da sociedade do espetáculo, nem seria preciso enfatizar o peso do imaginário como uma força que molda as percepções, as opiniões, o comportamento e o sentido do mundo. Imaginário da mercadoria, lembremos, que tem na propaganda sua verdadeira cultura, e que tende ao homogêneo e linear, de jeito nenhum ao plural e aberto, convidando ao feliz convívio de diferentes linguagens, culturas, etnias e visões de mundo. O que está à venda, no mundo todo, são, cada vez mais, imagens, e não diretamente coisas feitas e produzidas por quem trabalha. Estão à venda as marcas das grandes corporações, inseparáveis de estilos de vida que circulam pela vida social e são 
incorporados ao mundo da mercadoria (BUENO, 2003, p.35).

[v] "[...] a sociedade do espetáculo cria uma relação nova, e bastante estranha, entre passado, presente e futuro. Ao invés de uma acumulação crítica - em que se possa aprender com o trabalho das gerações que nos antecederam, formando a partir do presente uma crítica que projete um futuro diferente, que mereça algum dia o nome de civilização humana emancipada da necessidade e da violência -, temos um girar no vazio, uma sucessão de simulacros a se repetir, em um presente cansativo e monótono (BUENO, 2003, p.34). 